\title{
Seventeen-coordinate actinide helium complexes
}

DOI:

10.1002/anie.201700245

\section{Document Version}

Accepted author manuscript

Link to publication record in Manchester Research Explorer

\section{Citation for published version (APA):}

Kaltsoyannis, N. (2017). Seventeen-coordinate actinide helium complexes. Angewandte Chemie - International Edition, 56, 7066-7069. https://doi.org/10.1002/anie.201700245

\section{Published in:}

Angewandte Chemie - International Edition

\section{Citing this paper}

Please note that where the full-text provided on Manchester Research Explorer is the Author Accepted Manuscript or Proof version this may differ from the final Published version. If citing, it is advised that you check and use the publisher's definitive version.

\section{General rights}

Copyright and moral rights for the publications made accessible in the Research Explorer are retained by the authors and/or other copyright owners and it is a condition of accessing publications that users recognise and abide by the legal requirements associated with these rights.

\section{Takedown policy}

If you believe that this document breaches copyright please refer to the University of Manchester's Takedown Procedures [http://man.ac.uk/04Y6Bo] or contact uml.scholarlycommunications@manchester.ac.uk providing relevant details, so we can investigate your claim.

\section{OPEN ACCESS}




\title{
Seventeen-coordinate actinide complexes
}

\author{
Nikolas Kaltsoyannis
}

\begin{abstract}
The geometries and electronic structures of molecular ions featuring $\mathrm{He}$ atoms complexed to actinide cations are explored computationally using density functional and coupled cluster theories. A new record coordination number is established, as $\mathrm{AcHe}_{17}{ }^{3+}$, $\mathrm{ThHe}_{17}{ }^{4+}$ and $\mathrm{PaHe}_{17}{ }^{4+}$ are all found to be true geometric minima, with the He atoms clearly located in the first shell around the actinide. Analysis of $\mathrm{AcHe}_{n}^{3+}(n=1-17)$ using the Quantum Theory of Atoms in Molecules (QTAIM) confirms these systems as having closed shell, charge-induced dipole bonding. Excellent correlations $\left(R^{2}>0.95\right)$ are found between QTAIM metrics (bond critical point electron densities and delocalisation indices) and the average $\mathrm{Ac}-\mathrm{He}$ distances, and also with the incremental He binding energies.
\end{abstract}

The concept of coordination number $(\mathrm{CN})$ is very important in chemistry. It dates back to 1893 , when Alfred Werner defined it as the total number of neighbors around a central atom in a molecule or ion. ${ }^{[1]}$ Although this definition has been refined - for example to accommodate ligands such as ethene or cyclopentadienyl, which are taken to occupy one and three coordination sites respectively - the concept of $\mathrm{CN}$ has stood the test of time.

The current highest $\mathrm{CN}$ in molecular chemistry is 16 . This has been seen very recently in the experimental work of Pollak et al., ${ }^{[2]}$ who found $16 \mathrm{Cs} \cdots \mathrm{F}$ contacts in $\mathrm{Cs}\left[\mathrm{H}_{2} \mathrm{NB}_{2}\left(\mathrm{C}_{6} \mathrm{~F}_{5}\right)_{6}\right]$, and that by Popov et al. in $\mathrm{CoB}_{16}{ }^{-},{ }^{[3]}$ and has also been predicted theoretically by $\mathrm{Gu}$ et al..$^{[4]}$ for $\mathrm{M} @ \mathrm{Li}_{16}(\mathrm{M}=\mathrm{Ca}, \mathrm{Sr}, \mathrm{Ba}, \mathrm{Ti}, \mathrm{Zr}$ and $\mathrm{Hf})$. The record for the actinide elements stood at 14 for many years (in $\left.\mathrm{U}\left(\mathrm{BH}_{4}\right)_{4}\right),{ }^{[5]}$ but is now 15 , established experimentally by Daly et al. for $\mathrm{Th}\left(\mathrm{H}_{3} \mathrm{BNMe}_{2} \mathrm{BH}_{3}\right)_{4},{ }^{[6]}$ although the same authors used density functional theory (DFT) to predict that in the gas phase the number of Th..H contacts could rise to 16 .

All of these contributions make reference to the work of Hermann et al..$^{[7]}$ who, in 2007, published in this journal a DFT survey of the geometric structures of $\mathrm{Pb}^{2+}$ coordinated by $\mathrm{He}$ atoms. The maximum value of $n$ in $\mathrm{PbHe}_{n}^{2+}$ was found to be 15 , with no true minimum structures being located for $n>15$ in which all the $\mathrm{He}$ atoms are located in the first shell around the $\mathrm{Pb}$. Intriguingly, buried at the end of the Methods section, Hermann et al. write "We note that higher coordination number might be expected for charged actinide-He interactions". I can now report that this suggestion is correct, and that

[a] Professor Nikolas Kaltsoyannis School of Chemistry

The University of Manchester

Oxford Road, Manchester M13 9PL, UK

E-mail: nikolas.kaltsoyannis@manchester.ac.uk

Supporting information for this article is given via a link at the end of the document. computationally stable one-shell $\mathrm{AnHe}_{n}{ }^{q_{+}}$structures exist for $\mathrm{Ac}^{3+}, \mathrm{Th}^{4+}$ and $\mathrm{Pa}^{4+}$ in which $n=17$, a new record $\mathrm{CN}$.

As noted by Hermann et al., candidate metals for extensive He coordination should be large and positively charged, and the early actinides in their typical oxidation states certainly fit that description. In order to establish a robust method for exploring $\mathrm{PbHe}_{n}{ }^{2+}$ structures, Hermann et al. calculated potential curves for the interaction of $\mathrm{Pb}^{2+}$ with a single $\mathrm{He}$ atom, and showed that the Generalized Gradient Approximation (GGA) functional PW91, in conjunction with the modest aug-cc-pVDZ basis set, matches very closely the result from high-level $a b$ initio coupled cluster $(\operatorname{CCSD}(T))$ calculations using the much larger aug-ccpVQZ bases ${ }^{[7]}$ I have adopted a similar approach, and show in Figure 1 representative results for the parent actinide actinium in its group valence; the binding energy $\left(E_{\mathrm{B}}\right)$ of $\mathrm{Ac}^{3+}$ with $\mathrm{He}$, calculated at both DFT and $\operatorname{CCSD}(\mathrm{T})$ levels, is plotted against $r_{\mathrm{Ac}-\mathrm{He}}$ from 2 to $5 \AA$. For a system well described by a single reference electronic configuration, such as He coordinating to a closed shell metal ion, $\operatorname{CCSD}(\mathrm{T})$ in conjunction with a large basis set will give essentially exact results. $\operatorname{CCSD}(\mathrm{T}) T_{1}$ diagnostics are very low for $\mathrm{AcHe}^{3+}$ (aug-cc-pV5Z for $\mathrm{He}$ ) at its equilibrium geometry and at $5 \AA, 0.003$ and 0.002 respectively, confirming the single configuration description.

My results are somewhat different from those for $\mathrm{PbHe}^{2+}$ GGA DFT (PBE) with the aug-cc-pVDZ He basis is now very similar to $\operatorname{CCSD}(T)$ with the same small basis set. Increasing the He basis set quality in the $\operatorname{CCSD}(T)$ calculations leads, as would be expected, to a deepening of the potential well, giving $E_{\mathrm{B}}=-35.0 \mathrm{~kJ} \mathrm{~mol}^{-1}$ at $2.552 \AA$ for He with the very large aug-ccpV5Z basis set. Hence, unlike PbHe ${ }^{2+}$, GGA DFT with a modest basis set does not well reproduce $\operatorname{CCSD}(T)$ with a big basis for $\mathrm{AcHe}^{3+}$. As increasing the $\mathrm{He}$ basis quality with PBE makes very little difference to the potential well, I explored many other types of DFT to see if any could replicate the CCSD(T)/aug-cc-pV5Z data. This survey included GGA, hybrid, meta-GGA, meta-hybrid and double hybrid functionals, including where appropriate dispersion corrections, but none matched $\operatorname{CCSD}(\mathrm{T})$ /aug-ccpV5Z well. As is typical, LDA (SVN5) overbinds the system but, amusingly, the venerable exchange-only local spin density Slater functional (here denoted HFS) matches $\operatorname{CCSD}(\mathrm{T})$ /aug-ccpV5Z almost exactly, as shown in Figure 1. I have therefore explored $\mathrm{AcHe}_{n}{ }^{3+}$ structures using the HFS/aug-cc-pVDZ approach and, recognizing that this is an unusual method in modern quantum chemistry, have also conducted analogous calculations with the very widely used PBE functional. As we shall see, the results are similar. 


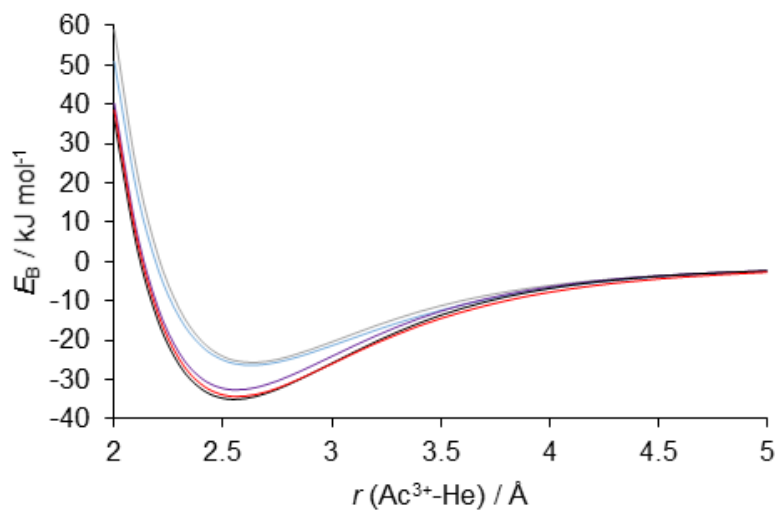

Figure 1. Potential energy curves for $\mathrm{AcHe}^{3+}$ using various theoretical methods. In all cases the Ac basis set is the same (the Stuttgart relativistic pseudopotential and accompanying polarised quadruple zeta valence basis set $\left.{ }^{[8]}\right)$. The method/He basis is as follows: blue; PBE/aug-cc-pVDZ, grey; $\operatorname{CCSD}(T) /$ aug-cc-pVDZ, purple; CCSD(T)/aug-cc-pVQZ, black; CCSD(T)/augcc-pV5Z, red; HFS/aug-cc-pVDZ. Analogous CCSD(T)/aug-cc-pV5Z and HFS/aug-cc-pVDZ curves for $\mathrm{AcHe}_{2}{ }^{3+}$ are given in the supporting information.

As with $\mathrm{PbHe}_{n}{ }^{2+}$, true minimum $\mathrm{AcHe}_{n}{ }^{3+}$ structures can be located for $n=1-15$; ball and stick representations of these, and their Cartesian atomic coordinates, are provided for the HFS calculations in the supporting information. As noted above, Hermann et al. concluded that if $n$ is increased to 16 or higher, no true minimum structure could be obtained for $\mathrm{PbHe}_{n}{ }^{2+}$ in which all the $\mathrm{He}$ atoms are positioned in the first shell around the $\mathrm{Pb}$ atom. By contrast, I now report that this is not the case for $\mathrm{AcHe}_{n}{ }^{3+}$. In this system, both the HFS and the PBE functionals find true minimum first shell structures for $n=16$ and 17. Ball and stick representations of the HFS structures are shown in Figure 2; to the best of my knowledge, $\mathrm{AcHe}_{17^{3+}}$ features the highest $\mathrm{CN}$ yet established. As can be seen in Table 1, the average Ac-He distances increase by just over $0.1 \AA$ from $n=1$ to $n=17$. This is not unexpected as more He atoms coordinate to the metal center. Even for $\mathrm{AcHe}_{17}{ }^{3+}$, however, the spread of Ac-He distances is very small $(0.031 \AA)$, clearly showing that all $17 \mathrm{He}$ atoms are indeed in the first coordination shell. All attempts to coordinate an $18^{\text {th }} \mathrm{He}$ atom in the first coordination shell failed.

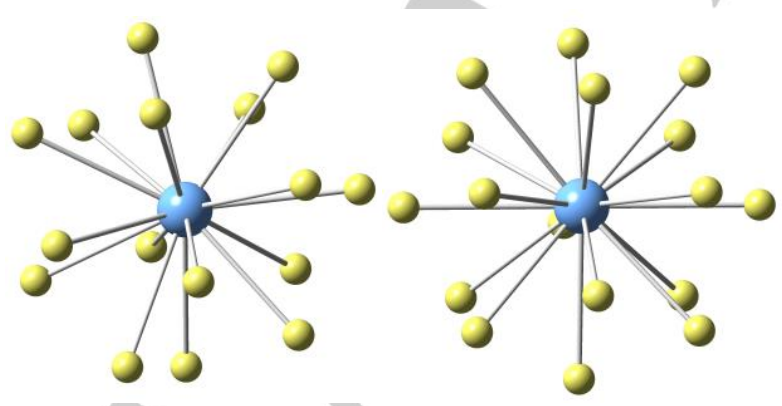

Figure 2. Optimised (HFS) structures of $\mathrm{AcHe}_{16}{ }^{3+}$ (left) and $\mathrm{AcHe}_{17} 7^{3+}$ Cartesian atomic coordinates are provided in the supporting information.
Table 1. Average, minimum and maximum Ac-He distances $(r, \AA)$, and ranges, in $\mathrm{HFS} \mathrm{AcHe}_{n}^{3+}(n=1-17)$.

\begin{tabular}{lllll}
\hline$n$ & $r_{\mathrm{av}}$ & $r_{\min }$ & $r_{\max }$ & $r_{\max } r_{\min }$ \\
\hline 1 & 2.564 & - & - & - \\
2 & 2.570 & 2.570 & 2.570 & 0.000 \\
3 & 2.576 & 2.576 & 2.576 & 0.000 \\
4 & 2.575 & 2.572 & 2.579 & 0.007 \\
5 & 2.573 & 2.570 & 2.576 & 0.007 \\
6 & 2.588 & 2.581 & 2.594 & 0.014 \\
7 & 2.588 & 2.582 & 2.598 & 0.016 \\
8 & 2.592 & 2.582 & 2.602 & 0.020 \\
9 & 2.593 & 2.583 & 2.601 & 0.018 \\
10 & 2.599 & 2.586 & 2.607 & 0.021 \\
11 & 2.603 & 2.590 & 2.608 & 0.017 \\
12 & 2.607 & 2.607 & 2.608 & 0.002 \\
13 & 2.617 & 2.611 & 2.632 & 0.021 \\
14 & 2.626 & 2.609 & 2.631 & 0.023 \\
15 & 2.637 & 2.619 & 2.647 & 0.027 \\
16 & 2.654 & 2.619 & 2.666 & 0.047 \\
17 & 2.671 & 2.664 & 2.695 & 0.031 \\
\hline
\end{tabular}

The incremental He binding energy $\left|E_{\mathrm{IB}}(n)\right|$ is shown in Figure 2 for both HFS and PBE functionals. It is calculated from equation (1), in which $\mathrm{E}(n)$ is the total (SCF) energy of $\mathrm{AcHe}_{n}{ }^{3+}$ and $E(\mathrm{He})$ is the total energy of $\mathrm{He} . E_{\mathrm{IB}}(n)$ is the energy gain upon attaching a $\mathrm{He}$ atom to $\mathrm{AcHe}_{n-1}{ }^{3+}$.

$$
E_{\mathrm{BB}}(n)=\mathrm{E}(n)-\mathrm{E}(n-1)-\mathrm{E}(\mathrm{He})
$$

The trend for both HFS and PBE is very similar, and is like that reported by Hermann et al. for $\mathrm{PbHe}_{n}{ }^{2+}$. There is a gradual decrease, in absolute terms, to $n=11$. Hermann et al. note that the special stability of the icosahedral $n=12$ structure leads to a local maximum in the $\left|E_{\mathrm{IB}}(n)\right|$ graph for $\mathrm{PbHe}_{12}{ }^{2+}$, which is also seen for $\mathrm{AcHe}_{12}{ }^{3+}$ at the PBE level. More notable, however, is the reduction in $E_{\mathrm{IB}}$ at $\mathrm{AcHe}_{13}{ }^{3+}$, particularly for the PBE data, reflecting the disruption of the $n=12$ complex. Hermann et al. attribute the slight increase at $n=14$ to it being another especially stable structure. After this point the gradient of both lines steepens, as the first coordination shell saturates.

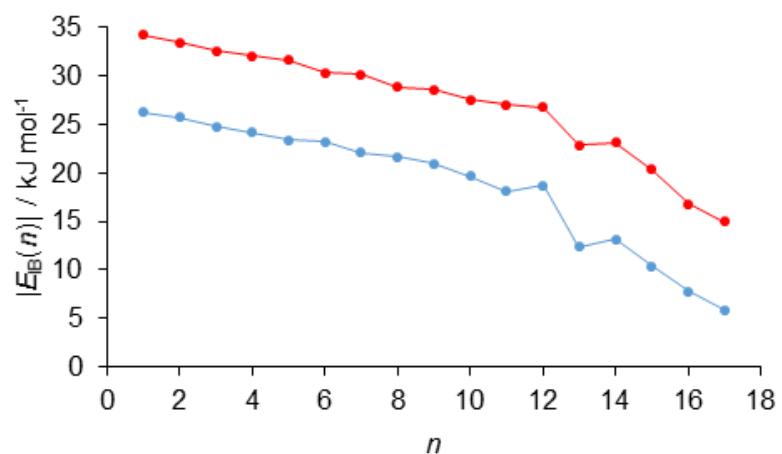


Figure 2. $\left|E_{\mathrm{IB}}(n)\right|$ for $\mathrm{AcHe}_{n}{ }^{3+}(n=1-17)$. Red: HFS, blue: PBE. The data on which this graph is based, and analogous $\operatorname{CCSD}(\mathrm{T})$ data for $n=1-4$, are given in the supporting information.

For a number of years now, my group has employed the Quantum Theory of Atoms in Molecules (QTAIM) ${ }^{[9]}$ to study the bonding in $5 f$ compounds, ${ }^{[10]}$ as well as to quantify the strength of actinide-element bonds. ${ }^{[11]}$ QTAIM data for $\mathrm{AcHe}_{n}{ }^{3+}(n=1-$ 17) are collected in Table 2. Hermann et al. note that the $\mathrm{Pb}^{2+}$ $\mathrm{He}$ interaction is primarily of the charge-induced dipole type, in which there is only minimal transfer of charge from $\mathrm{He}$ to $\mathrm{Pb}^{2+}$. The partial atomic charges in Table 2 indicate that this description is also appropriate for $\mathrm{AcHe}_{n}{ }^{3+}$; only very little of the overall $3+$ charge is acquired by any given $\mathrm{He}$ atom, unsurprising given its extremely high ionisation energy $(24.6 \mathrm{eV})$ Addition of successive $\mathrm{He}$ atoms to the complex results in a gradual decrease in the partial charge of the Ac center, and this decrease for successive $\mathrm{He}$ addition becomes smaller until a limiting value of c. +2.65 is reached for the largest systems. The very small bond critical point electron densities confirm the closed shell nature of the Ac $\cdots$ He interactions, as do the energy densities, which average 0.003 in all seventeen systems. The delocalization indices - QTAIM measures of bond order - are clearly very small. $\rho$ and $\delta_{\mathrm{Ac}, \mathrm{He}}$ decrease slightly with $n$, reflecting the lengthening of the Ac-He distances. Indeed, $R^{2}$ for the correlation of the average $r_{\mathrm{Ac}-\mathrm{He}}($ Table 1$)$ with $\rho$ and $\delta_{\mathrm{Ac}, \mathrm{He}}$ is 0.996 and 0.953 respectively.

Table 2. QTAIM atomic charges $q$, average Ac-He bond critical point electron densities $\rho$ (atomic units), and Ac-He delocalisation indices $\delta$, in $\mathrm{HFS} \mathrm{AcHe}_{n}{ }^{3+}$ $(n=1-17)$

\begin{tabular}{lllll}
\hline$n$ & $q_{\mathrm{Ac}}$ & $q_{\mathrm{He}}(\mathrm{av})$ & $\rho(\mathrm{av})$ & $\delta \mathrm{Ac}, \mathrm{He}(\mathrm{av})$ \\
\hline 1 & 2.966 & 0.034 & 0.021 & 0.132 \\
2 & 2.933 & 0.034 & 0.020 & 0.130 \\
3 & 2.902 & 0.033 & 0.020 & 0.128 \\
4 & 2.872 & 0.032 & 0.020 & 0.124 \\
5 & 2.843 & 0.031 & 0.020 & 0.119 \\
6 & 2.819 & 0.030 & 0.019 & 0.119 \\
7 & 2.793 & 0.030 & 0.019 & 0.116 \\
8 & 2.769 & 0.029 & 0.019 & 0.113 \\
9 & 2.746 & 0.028 & 0.019 & 0.110 \\
10 & 2.725 & 0.028 & 0.019 & 0.108 \\
11 & 2.704 & 0.027 & 0.019 & 0.106 \\
12 & 2.683 & 0.026 & 0.018 & 0.104 \\
13 & 2.673 & 0.025 & 0.018 & 0.099 \\
14 & 2.662 & 0.024 & 0.018 & 0.095 \\
15 & 2.655 & 0.023 & 0.017 & 0.090 \\
16 & 2.652 & 0.022 & 0.017 & 0.085 \\
17 & 2.653 & 0.020 & 0.016 & 0.080 \\
\hline
\end{tabular}

The extent to which QTAIM metrics correlate with actinideelement bond strength is very variable, ranging from essentially uncorrelated to highly so. For more detailed information, the reader is directed to references $11 . \mathrm{AcHe}_{n}{ }^{3+}$ provide an opportunity to probe this further in an atypical bonding situation. Correlations of $\rho$ and $\delta_{\mathrm{Ac}, \mathrm{He}}$ with $\left|E_{\mathrm{BB}}(n)\right|$ are very high, with $R^{2}$ values of 0.989 and 0.960 respectively. Thus the QTAIM metrics are very good guides to the strength of the closed shell, charge-induced dipole bonding of $\mathrm{He}$ atoms to the spherically symmetric $\mathrm{Ac}^{3+}$. The average Ac-He distance also correlates extremely well with $\left|E_{\mathrm{IB}}(n)\right|, R^{2}=0.989$.

Hermann et al. conclude the main text of their contribution by noting "The stability of $\mathrm{PbHe}_{15}{ }^{2+}$ suggests that it can be identified by mass spectrometric methods." The present data indicate a somewhat larger stability for $\mathrm{AcHe}_{17^{3+}}$, but the scarcity and radioactivity of Ac are such that experimental studies are unlikely. I therefore extended my search to the next elements in periodic table, Th, $\mathrm{Pa}$ and $\mathrm{U}$, both to explore the generality of the Ac conclusions and also to find more plausible candidates for experimental investigation. For $U$, no stable one-shell structures were located for $\mathrm{UHe}_{n}{ }^{q+}(q=2-6)$ with $n>15$. This is also true for $\mathrm{Pa}^{5+}$, but $\mathrm{PaHe}_{17}{ }^{4+}$ does retain all of the $\mathrm{He}$ atoms in the first coordination shell, albeit with a wider range of metal-He distances than for the Ac analogue $(2.47-2.61 \AA)$. The average $\mathrm{Pa}-\mathrm{He} E_{\mathrm{B}}$ in this system is $-64.0 \mathrm{~kJ} \mathrm{~mol}^{-1}$, significantly larger than that for $\mathrm{AcHe}_{17}{ }^{3+}\left(-27.1 \mathrm{~kJ} \mathrm{~mol}^{-1}\right)$ as expected given the smaller charge of the metal ion in the latter. Experimental $\mathrm{Pa}$ chemistry is also highly challenging, but that of Th is much less so, and hence I was pleased to find that both $\mathrm{ThHe}_{17}{ }^{3+}$ and $\mathrm{ThHe}_{17^{4+}}$ are stable structures at the HFS and PBE levels. Cartesian coordinates of $\mathrm{AnHe}_{17}{ }^{q+}(\mathrm{An}=\mathrm{Th}, q=3,4 ; \mathrm{An}=\mathrm{Pa}, q$ $=4$ ) are provided in the supporting information. $\mathrm{ThHe}_{17}{ }^{3+}$ has a much wider range of metal-He distances than either $\mathrm{AcHe}_{17}{ }^{3+}$ or $\mathrm{PaHe}_{17}{ }^{4+}(2.67-2.94 \AA)$, making its description as a genuine $\mathrm{CN}$ 17 structure debatable, but the geometry of $\mathrm{ThHe}_{17}{ }^{4+}$ is very similar to that of $\mathrm{AcHe}_{17^{3+}}$, with Th-He distances in the range 2.54-2.59 $\AA$, and an average Th-He $E_{B}$ of $-65.2 \mathrm{~kJ} \mathrm{~mol}^{-1}$. $\mathrm{ThHe}_{17^{4+}}$ is therefore the most likely of the new CN 17 systems to be experimentally accessible.

\section{Computational Details}

All DFT calculations were performed with the Gaussian 09 code, revision D.01. ${ }^{[12]}(14 s$ 13p 10d $8 f 5 g) /[10 s 9 p 5 d 4 f 3 g]$ segmented valence basis sets with Stuttgart-Bonn variety relativistic pseudopotentials were used for the actinides, ${ }^{[8]}$ and the aug-cc-pVXZ $(X=D, Q, 5)$ basis sets were employed for $\mathrm{He}$, as discussed in the main text. For the production calculations, the HFS ${ }^{[13]}$ and $\mathrm{PBE}^{[14]}$ functionals were used, in conjunction with the ultrafine integration grid. The standard SCF convergence criterion $\left(10^{-8}\right)$ was used. All geometry optimisations were performed without symmetry constraints, and the geometry convergence criteria were tightened from the default via $\operatorname{IOP}(6 / 7=67)$, which produces $10^{-4}$ au for the maximum force. The resulting structures were verified as true minima via harmonic vibrational frequency analysis. QTAIM analyses were performed using the AIMALL program package, ${ }^{[15]}$ with .wfx files generated in Gaussian 09 used as input. CCSD(T) calculations were performed using the Molpro 2015.1 code, with all default settings. ${ }^{[16]}$

\section{Acknowledgements}

I am grateful to Dr Hanshi Hu for bringing the work of Hermann et al. $^{[7]}$ to my attention, and to the University of Manchester's Computational Shared Facility for computational resources. 
Keywords: coordination number $\cdot$ actinide $\cdot$ density functional $•$ actinium $\bullet \operatorname{CCSD}(\mathrm{T}) \cdot \mathrm{QTAIM}$

[1] A. Werner, Z. Anorg. Chem. 1893, 3, 267.

[2] D. Pollak, R. Goddard, K. R. Porschke, J. Am. Chem. Soc. 2016, 138, 9444.

[3] I. A. Popov, T. Jian, G. V. Lopez, A. I. Boldyrev, L. S. Wang, Nat Comm. 2015, 6 .

[4] X. Gu, G. H. Chen, M. Ji, Y. X. Yao, X. G. Gong, Nanoscale 2012, 4, 2567.

[5] E. R. Bernstein, J. Lippard, J. J. Mayerle, T. A. Keiderling, W. C Hamilton, S. J. Laplaca, Inorg. Chem. 1972, 11, 3009.

[6] S. R. Daly, P. M. B. Piccoli, A. J. Schultz, T. K. Todorova, L. Gagliardi, G. S. Girolami, Angew. Chem. Int. Ed. 2010, 49, 3379.

[7] A. Hermann, M. Lein, P. Schwerdtfeger, Angew. Chem. Int. Ed. 2007, 46, 2444.

[8] X. Y. Cao, M. Dolg, J. Mol. Struct. (TheoChem) 2004, 673, 203.

[9] R. F. W. Bader, Atoms in Molecules: A Quantum Theory, OUP, Oxford, 1990.

[10] a) P. L. Arnold, A. Prescimone, J. H. Farnaby, S. M. Mansell, S. Parsons, N. Kaltsoyannis, Angew. Chem. Int. Ed. 2015, 54, 6735; b) M. S. Dutkiewicz, J. H. Farnaby, C. Apostolidis, E. Colineau, O. Walter, N Magnani, M. G. Gardiner, J. B. Love, N. Kaltsoyannis, R. Caciuffo, P. L. Arnold, Nat. Chem. 2016, 8, 797; c) N. Kaltsoyannis, Inorg. Chem. 2013, 52, 3407; d) N. Kaltsoyannis, Dalton Trans. 2016, 45, 3158; e) D. E. Smiles, G. Wu, N. Kaltsoyannis, T. W. Hayton, Chem. Sci. 2015, 6, 3891.
[11] a) Q.-R. Huang, J. R. Kingham, N. Kaltsoyannis, Dalton Trans. 2015 44, 2554; b) A. R. E. Mountain, N. Kaltsoyannis, Dalton Trans. 2013, 42, 13477 ; c) K. T. P. O'Brien, N. Kaltsoyannis, Dalton Trans. 2017, 46, 760.

[12] M. J. Frisch, G. W. Trucks, H. B. Schlegel, G. E. Scuseria, M. A. Robb, J. R. Cheeseman, G. Scalmani, V. Barone, B. Mennucci, G. A. Petersson, H. Nakatsuji, M. Caricato, X. Li, H. P. Hratchian, A. F. Izmaylov, J. Bloino, G. Zheng, J. L. Sonnenberg, M. Hada, M. Ehara, K. Toyota, R. Fukuda, J. Hasegawa, M. Ishida, T. Nakajima, Y. Honda, O Kitao, H. Nakai, T. Vreven, J. Montgomery, J. A., J. E. Peralta, F. Ogliaro, M. Bearpark, J. J. Heyd, E. Brothers, K. N. Kudin, V. N. Staroverov, R. Kobayashi, J. Normand, K. Raghavachari, A. Rendell, J. C. Burant, S. S. Iyengar, J. Tomasi, M. Cossi, M. Rega, N. J. Millam, M. Klene, J. E. Knox, J. B. Cross, V. Bakken, C. Adamo, J. Jaramillo, R. E. Gomperts, O. Stratmann, A. J. Yazyev, R. Austin, C. Cammi, J. W. Pomelli, R. Ochterski, R. L. Martin, K. Morokuma, V. G. Zakrzewski, G. A. Voth, P. Salvador, J. J. Dannenberg, S. Dapprich, A. D. Daniels, O. Farkas, J. B. Foresman, J. V. Ortiz, J. Cioslowski, D. J. Fox, Gaussian, Inc., Wallingford CT, 2013.

[13] a) P. Hohenberg, W. Kohn, Phys. Rev. 1964, B136, 864; b) W. Kohn, L. J. Sham, Phys. Rev. 1965, A140, 1133.

[14] J. P. Perdew, K. Burke, M. Ernzerhof, Phys. Rev. Lett. 1996, 77, 3865.

[15] T. A. Keith, AIMAll 16.01.09, TK Gristmill Software, http://aim.tkgristmill.com 2016.

[16] H. J. Werner, P. J. Knowles, G. Knizia, F. R. Manby, M. Schutz, Wiley Interdiscip. Rev.-Comput. Mol. Sci. 2012, 2, 242. 


\section{COMMUNICATION}

$\mathrm{AcHe}_{17} 7^{3+}, \mathrm{ThHe}_{17^{4+}}$ and $\mathrm{PaHe}_{17^{4+}}$ have stable, one-shell true minimum structures with the highest coordination number yet reported.

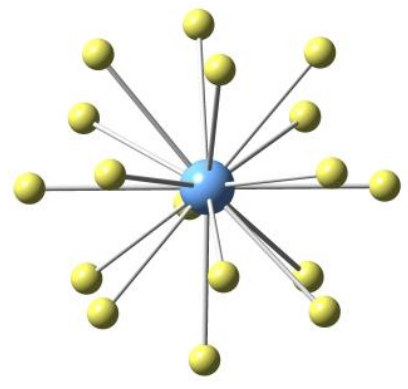

Nikolas Kaltsoyannis

Page No. - Page No.

Seventeen-coordinate actinide complexes 